\title{
Visual hallucinations in Alzheimer's disease do not seem to be associated with chronic hypoperfusion of to visual processing areas V2 and V3 but may be associated with reduced cholinergic input to these areas
}

\author{
Lindsey Isla Sinclair ${ }^{1,2^{*}}$, Amit Kumar ${ }^{3}$, Taher Darreh-Shori ${ }^{3}$ and Seth Love ${ }^{2}$
}

\begin{abstract}
Background: Up to 20\% of patients with AD experience hallucinations. The pathological substrate is not known. Visual hallucinations $(\mathrm{VH})$ are more common in dementia with Lewy bodies (DLB). In autopsy studies, up to 60\% of patients with AD have concomitant Lewy body pathology. Decreased perfusion of the occipital lobe has been implicated in DLB patients with $\mathrm{VH}$, and post-mortem studies point to both decreased cholinergic activity and reduced oxygenation of the occipital cortex in DLB.
\end{abstract}

Methods: We used biochemical methods to assess microvessel density (level of von Willebrand factor, a marker of endothelial cell content), ante-mortem oxygenation (vascular endothelial growth factor, a marker of tissue hypoxia; myelin-associated glycoprotein to proteolipid protein-1 ratio, a measure of tissue oxygenation relative to metabolic demand), cholinergic innervation (acetylcholinesterase and choline acetyltransferase), butyrylcholinesterase and insoluble a-synuclein content in the BA18 and BA19 occipital cortex obtained post-mortem from 23 AD patients who had experienced visual hallucinations, 19 AD patients without hallucinations, 19 DLB patients, and 36 controls. The cohorts were matched for age, gender and post-mortem interval.

Results: There was no evidence of reduced microvessel density, hypoperfusion or reduction in ChAT activity in AD with visual hallucinations. Acetylcholinesterase activity was reduced in both BA18 and BA19, in all 3 dementia groups, and the concentration was also reduced in BA19 in the DLB and AD without visual hallucinations groups. Insoluble a-synuclein was raised in the DLB group in both areas but not in AD either with or without visual hallucinations.

Conclusions: Our results suggest that visual hallucinations in $A D$ are associated with cholinergic denervation rather than chronic hypoperfusion or a-synuclein accumulation in visual processing areas of the occipital cortex.

Keywords: Dementia, Alzheimer's disease, Visual hallucinations, Vascular endothelial growth factor, Myelin-associated glycoprotein, PLP1, von Willebrand factor, Acetylcholine, Post-mortem tissue

\section{Introduction}

Alzheimer's disease (AD) is the most common form of late-life dementia. Its incidence is set to nearly triple by 2050, due to the ageing of the population [1]. As with all dementias, it has a devastating effect on patients and those around them. The pathological hallmarks of $\mathrm{AD}$

\footnotetext{
* Correspondence: eplis@bristol.ac.uk

${ }^{1}$ Population Health Sciences, Oakfield House, University of Bristol, Clifton, Bristol BS8 2BN, UK

${ }^{2}$ Translational Health Sciences, Level 1 Learning \& Research Building, Southmead Hospital, University of Bristol, Bristol BS10 5NB, UK Full list of author information is available at the end of the article
}

are neurofibrillary tangles and amyloid- $\beta$ plaques. Up to $20 \%$ of patients with AD experience hallucinations during their illness [2]. Current treatments for this can be ineffective, and antipsychotics are often used, which increase the risk of stroke and premature death [3].

Visual hallucinations can be very distressing for both patients and their relatives. They occur in most forms of dementia but are particularly common in dementia with Lewy bodies (DLB) [4]. The core pathology in DLB is the accumulation of $\alpha$-synuclein in Lewy bodies and Lewy neurites [5]. In autopsy studies, up to $60 \%$ of

(c) The Author(s). 2019 Open Access This article is distributed under the terms of the Creative Commons Attribution 4.0 International License (http://creativecommons.org/licenses/by/4.0/), which permits unrestricted use, distribution, and 
patients with $\mathrm{AD}$ had at least some concomitant Lewy body pathology [4]. Several studies have found that visual hallucinations are more likely in those with AD and Lewy body pathology [6-9]. One large study suggested that there was an $\mathrm{AD}$ plus Lewy body phenotype consisting of dementia with delusions, hallucinations and prominent motor problems [10].

Most of the work on the pathophysiology of visual hallucinations in dementia has been in DLB. Neuroimaging studies have shown decreased perfusion of the occipital lobe, a region of the cortex with only sparse Lewy bodies [11-13]. A PET study found reduced fluorodeoxyglucose uptake in the occipital cortex of individuals with DLB who had visual hallucinations [14]. A SPECT study which compared DLB to AD found reduced perfusion in the medial occipital lobe in DLB but not in AD [15]. Indeed reduced occipital lobe perfusion is now included as a supportive biomarker for the diagnosis of DLB [16]. Post-mortem studies have suggested decreased cholinergic activity in the visual cortex in DLB [17] and decreased oxygenation of the occipital cortex in DLB, which correlated with reduced microvessel density and was associated with decreased VEGF [18].

Acetylcholinesterase inhibitors such as donepezil have been shown to reduce visual hallucinations in DLB, although they do not help all patients [19]. A small uncontrolled study showed that donepezil increased occipital lobe perfusion on SPECT and decreased hallucinations [20]. Work in myocytes has suggested an intriguing direct link between cholinergic stimulation and VEGF level [21]. It is also known that cholinergic stimulation causes vasodilatation [22].

Current theories of the basis of visual hallucinations in dementia include the perception and attention deficit model, which proposes a lack of integration of incoming sensory information and top-down prior knowledge/expectation [23]. It has advantages over other models, e.g. the misidentification model, in that it better accounts all of the observed phenomena in different disease states. This model implicates the ventral visual stream in the recurrent complex visual hallucinations seen in DLB as this stream is more involved in object-based attention. It has been suggested that cholinergic input modulates the interaction between bottom-up perceptions and top-down processing and also modulates the level of certainty of topdown information. The authors suggested that cholinergic deficits lead to over-processing of top-down information leading to visual hallucinations [24]. An imbalance between serotonin and acetylcholine (ACh) has also been implicated in visual hallucinations [25].

We set out to determine whether visual hallucinations in $\mathrm{AD}$ result from Lewy body pathology or chronic hypoperfusion affecting the visual processing areas in the occipital cortex. Given that acetylcholinesterase inhibitors reduce visual hallucinations (at least to some extent) and the suggestion of a direct link between cholinergic input and vessel profusion, we also assessed cholinergic input, by measuring the 3 enzymes involved in the production and breakdown of ACh (see Fig. 1). We previously demonstrated that the ratio of the hypoxia-sensitive myelin-associated glycoprotein (MAG) to the hypoxia-resistant proteolipid oprotein-1 (PLP) is a robust measure of antemortem perfusion in relation to metabolic demand $[26$, 27]. Both myelin proteins are very stable under post-mortem conditions [26] and have half-lives of several months. A decline in the MAG:PLP1 ratio in post-mortem brain tissue reflects a reduction in ante-mortem oxygenation of the tissue over a period of several months prior to death. von Willebrand factor is a marker of microvessel (capillary) density, and VEGF is upregulated in hypoperfused tissue [18, 26-28]. We previously showed that VEGF and capillary density are reduced in the primary visual cortex in DLB [18].

In view of the evidence of reduced perfusion in the occipital lobes in patients with visual hallucinations, and the theoretical implication of visual processing areas in the occipital cortex, we decided to focus on V2 (BA18) and V3 (BA19). After V1 (BA17), the visual processing pathway splits into ventral and dorsal pathways (see Fig. 2). In the present study, we have assessed the ventral pathway, as this is postulated to be concerned with "what" is seen rather than the "where" that is processed via the dorsal pathway. There is evidence to suggest that the ventral pathway is more likely to be involved in visual hallucinations in DLB $[23,29]$.

We hypothesised that the occipital cortex from $\mathrm{AD}$ patients with visual hallucinations would show evidence of reduced perfusion as measured by the MAG:PLP1 ratio in V2 and V3 compared to controls and to AD patients without visual hallucinations.

\section{Methods}

The study used brain tissue and clinical data obtained from the South West Dementia Brain Bank (SWDBB), University of Bristol, with local Research Ethics Committee approval (REC reference 18/SW/0029). Comprehensive clinical summaries are recorded in the SWDBB database for all brain donors. The summaries are generated from the patient medical notes and from any additional information collected as part of the Brains for Dementia Research Programme. The summaries were searched using the following terms: psychosis, hallucinating, hallucinations, quetiapine, risperidone and visual. This allowed us to identify 24 individuals with neuropathologically confirmed $\mathrm{AD}$ who had definitely experienced visual hallucinations and 33 individuals with $\mathrm{AD}$ who had definitely not experienced visual hallucinations during their illness. We also selected 23 individuals with 


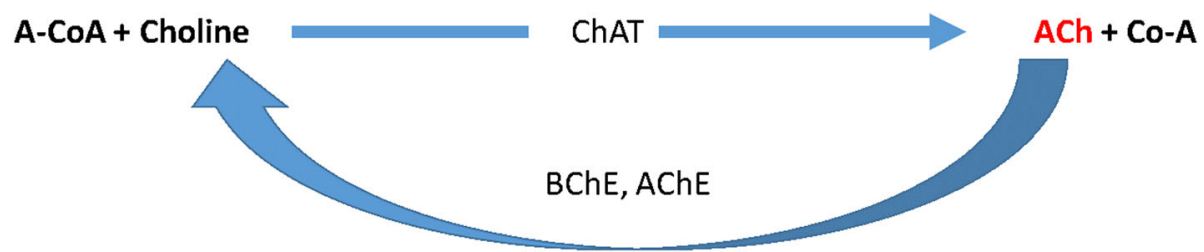

Fig. 1 Acetylcholine (ACh) is synthesised by choline acetyltransferase (ChAT) and broken down by acetylcholinesterase (AChE) at low concentrations and butyrylcholinesterase (BChE) at higher concentrations

neuropathologically confirmed dementia with Lewy bodies, 2 of whom had not and 21 who had experienced visual hallucinations, and 36 controls without dementia. We excluded individuals who had had major vascular abnormalities or vascular dementia as a primary diagnosis. Psychiatric, neurological and treatment histories for the individuals in this cohort are summarised in Additional file 1: Table S3. The cohorts were matched for age, gender and post-mortem interval. Braak tangle stage and severity of arteriolosclerotic small vessel disease and cerebral amyloid angiopathy had been assessed as described [26, 30].

Dementia was assessed clinically using DSM-IV criteria [31], and DLB was diagnosed according to consensus neuropathological criteria [4]. The right half of each brain had been fixed in formalin for 3 weeks prior to the detailed neuropathological examination, and the left half sliced and subdivided into multiple samples which were frozen at $80^{\circ} \mathrm{C}$. Neuropathological diagnoses of AD were made according to NIA-AA criteria [32]. Control individuals had no history of cognitive problems or psychosis during their lifetime and had no major neuropathological abnormalities on post-mortem examination other than mild neurofibrillary tangle pathology (Braak stage $\leq 3$ ) or scattered diffuse $A \beta$ plaques (see Table 1 for a summary of the characteristics of the cohorts). The cases selected for the dementia with Lewy bodies group had only "low AD neuropathologic change" which according to NIA-AA criteria [32] would not have accounted for dementia.

\section{Homogenate preparation}

Fresh frozen tissue was dissected from ventral BA18 and BA19 from the left occipital lobe. To produce the SDS homogenates used for most of the assays in this project, $200 \mathrm{mg}$ of tissue was homogenised in $1 \mathrm{ml}$ of chilled $1 \%$ SDS lysis buffer in a Precellys tissue homogeniser $(2 \times$ $15 \mathrm{~s}$ at $6000 \mathrm{~g}$ ) with $6-10$ zirconia beads in a $2-\mathrm{ml}$ homogenate tube. The homogenates were then centrifuged for $15 \mathrm{~min}$ at $13,000 \mathrm{~g}$ at $4{ }^{\circ} \mathrm{C}$. The supernatant was aliquoted into non-binding 96-well storage plates (Thermo Scientific) and frozen at $-80^{\circ} \mathrm{C}$ until required.

Choline acetyltransferase (ChAT) homogenates were prepared using a method adapted from that of Peng et al. [33]. Fifty to $100 \mathrm{mg}$ of fresh frozen tissue was placed in a 2-ml homogenate tube with 6-10 zirconia beads. The volume of all buffers in microlitres added was

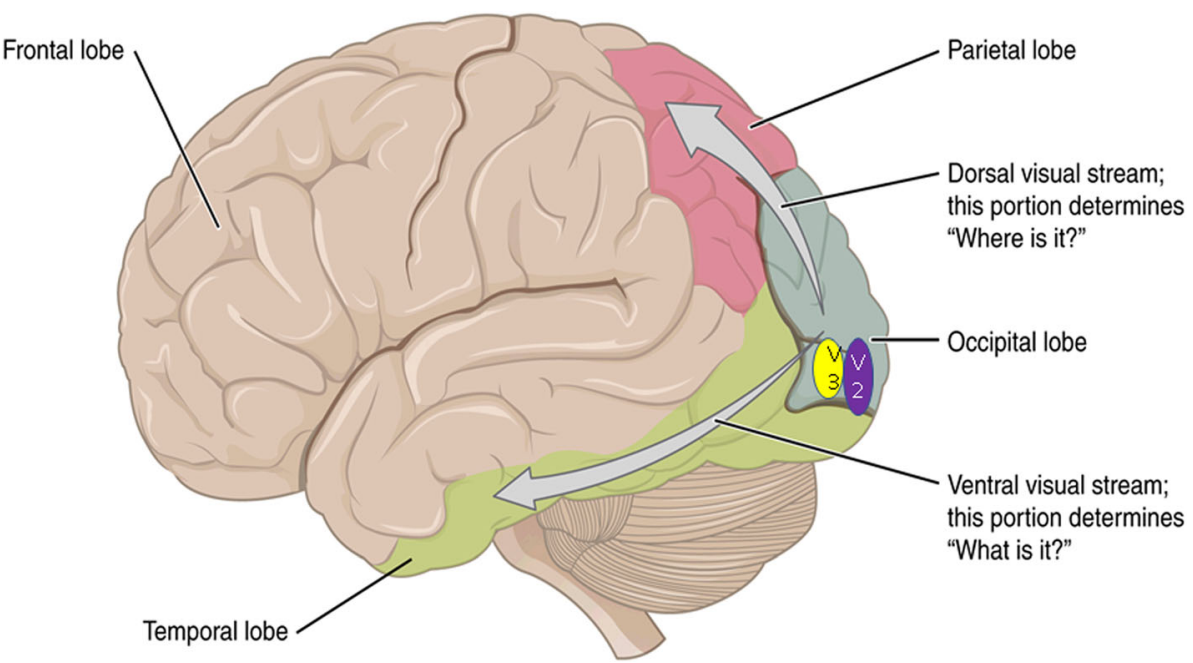

Fig. 2 The visual processing pathways in the brain. Ventral visual area V2 is shown in purple (BA18) and ventral visual area V3 is shown in yellow (BA19). Figure from the OpenStax Anatomy \& physiology textbook 2014 CCBY 3.0, available from https://cnx.org/contents/FPtK1zmh@12.16:KcreJ7oj@9/Central-Processing 
Table 1 Characteristics of the study cohort. Small vessel disease and cerebral amyloid angiopathy scoring were performed on a 4point scale [26, 30]. Although the cohorts were matched for age, gender and post-mortem interval, there was weak evidence of a between-group difference in age at death. Analyses were therefore carried out both with and without age as a covariate

\begin{tabular}{|c|c|c|c|c|c|c|c|c|c|c|}
\hline & \multicolumn{2}{|c|}{$\begin{array}{l}\text { AD with visual } \\
\text { hallucinations, } \\
n=23\end{array}$} & \multicolumn{2}{|c|}{$\begin{array}{l}\text { AD without } \\
\text { visual hallucinations, } \\
n=19\end{array}$} & \multicolumn{2}{|c|}{$\begin{array}{l}\text { Dementia } \\
\text { with Lewy bodies, } \\
n=19\end{array}$} & \multicolumn{2}{|c|}{$\begin{array}{l}\text { Controls, } \\
n=36\end{array}$} & \multirow[t]{2}{*}{ Statistical findings } & \multirow[t]{2}{*}{$\begin{array}{l}p \text { with age as } \\
\text { covariate }\end{array}$} \\
\hline & Mean & SD & Mean & SD & Mean & SD & Mean & SD & & \\
\hline Age (years) & 76.7 & 9.0 & 79.3 & 9.0 & 81.0 & 7.0 & 82.1 & 6.3 & ANOVA $p=0.065$ & \\
\hline Post-mortem interval (h) & 36.7 & 21.1 & 41.8 & 16.3 & 33.3 & 18.1 & 36.9 & 15.6 & ANOVA $p=0.533$ & \\
\hline $\begin{array}{l}\text { Age at onset of dementia } \\
\text { (years) }\end{array}$ & 66.9 & 10.4 & 66.4 & 10.1 & 73.0 & 6.9 & N/A & N/A & $\begin{array}{l}\text { Kruskal-Wallis } p=0.164, X^{2}= \\
3.611\end{array}$ & \\
\hline $\begin{array}{l}\text { Duration of dementia } \\
\text { (years) }\end{array}$ & 9.7 & 4.2 & 11.1 & 3.4 & 7.6 & 4.6 & N/A & N/A & ANOVA $p=0.04$ & 0.0340 \\
\hline Mean Braak stage & 5.5 & 0.5 & 5.3 & 0.9 & 3.1 & 1.5 & 2.0 & 0.8 & $x^{2}=109.9, p<0.001$ & \\
\hline \multicolumn{11}{|c|}{ Cerebral amyloid angiopathy score } \\
\hline 0 & 3 & & 3 & & 9 & & 24 & & $x^{2}=31.37, p<0.001$ & \\
\hline 1 & 7 & & 3 & & 3 & & 3 & & & \\
\hline 2 & 7 & & 8 & & 2 & & 3 & & & \\
\hline 3 & 6 & & 4 & & 5 & & 3 & & & \\
\hline \multicolumn{11}{|c|}{ Occipital small vessel disease score } \\
\hline 0 & 2 & & 2 & & 3 & & 8 & & $x^{2}=8.07, p=0.527$ & \\
\hline 1 & 11 & & 6 & & 5 & & 10 & & & \\
\hline 2 & 6 & & 3 & & 1 & & 6 & & & \\
\hline 3 & 0 & & 2 & & 1 & & 1 & & & \\
\hline
\end{tabular}

calculated as $15 \times$ the tissue weight in milligrams. Buffer A was $50 \mathrm{mM}$ potassium phosphate, $2 \mathrm{mM}$ EDTA, pH 7.4. Buffer B was $50 \mathrm{mM}$ potassium phosphate, $2 \mathrm{mM}$ EDTA, $500 \mathrm{mM} \mathrm{NaCl}$, pH 7.4. Buffer $\mathrm{C}$ was $50 \mathrm{mM}$ potassium phosphate, $2 \mathrm{mM}$ EDTA, $0.6 \%$ triton $\mathrm{X}-100, \mathrm{pH}$ 7.4. After each buffer was added, the tissue was homogenised for $2 \times 15 \mathrm{~s}$ at $6000 \mathrm{~g}$ in a Precellys tissue homogeniser and then spun for $30 \mathrm{~min}$ at $28,000 \times g$ at $4{ }^{\circ} \mathrm{C}$. The homogenisation was started with buffer A. The supernatant was removed, and the tissue re-homogenised and then re-centrifuged in the subsequent buffers. In this way, the fractions extracted were soluble ChAT (buffer A), ionic membrane-bound ChAT (buffer B) and membrane-bound ChAT (buffer C). The total ChAT homogenates used in the assays described below were prepared by adding equal volumes of each supernatant, e.g. $200 \mu \mathrm{l}$ supernatant A plus $200 \mu \mathrm{l}$ supernatant B plus $200 \mu \mathrm{l}$ supernatant C. As no protease inhibitors were used in the sample preparation, the whole operation was carried out with the samples either on ice or at $4{ }^{\circ} \mathrm{C}$. The samples were aliquoted out $(100 \mu \mathrm{l}$ per tube) and frozen at $-80^{\circ} \mathrm{C}$ until required. The reason for omitting protease inhibitors cocktail in the buffers is that one or several of these inhibitors also irreversibly inhibit the cholinergic enzymes (personal observations by TDS) and thereby would interfere with the downstream enzyme activity assessments.
The soluble and insoluble extracts used for the $\alpha$-synuclein assays were prepared in a third buffer. Up to $200 \mathrm{mg}$ of tissue was homogenised in $1 \mathrm{ml}$ of chilled TBS extraction buffer with $1 \%$ NP-40 (pH 7.4) in a Precellys tissue homogeniser $(2 \times 15 \mathrm{~s}$ at $6000 \mathrm{~g})$ with $6-10$ zirconia beads in a $2-\mathrm{ml}$ homogenate tube. The homogenates were then centrifuged for $15 \mathrm{~min}$ at $13,000 \mathrm{~g}$ at $4{ }^{\circ} \mathrm{C}$. The supernatants were removed and aliquoted into non-binding 96-well storage plates (Thermo Scientific) and frozen at $-80{ }^{\circ} \mathrm{C}$ until required. The pellet was resuspended in $400 \mu \mathrm{l}$ of guandicine $\mathrm{HCl}$ buffer (3 parts guanidine $\mathrm{HCl}$ to 1 part $50 \mathrm{mM}$ Tris, $\mathrm{pH} 8$ ), homogenised again in a Precellys tissue homogeniser $(2 \times 15 \mathrm{~s}$ at $6000 \mathrm{~g}$ ) and then spun for $15 \mathrm{~min}$ at $13,000 \mathrm{~g}$ at $4^{\circ} \mathrm{C}$. The supernatant was removed, aliquoted onto non-binding 96 well storage plates (Thermo Scientific) and frozen at $-80^{\circ} \mathrm{C}$ until required. Total protein was measured for all samples with a Coomassie Protein Plus kit (Thermo Scientific).

\section{Vascular endothelial growth factor ELISA}

VEGF was measured using a commercial kit (R\&D Systems Duoset DY293B) adapted for use in a 384-well Nunc MaxiSorp plate. Seventy-five microlitres of mouse anti-human VEGF capture antibody, diluted 1:120 in PBS, was added to each well. The plate was then sealed and incubated overnight at room temperature. Following 
$4 \times 3$-min washes with $0.05 \% \mathrm{PBS} /$ Tween per well, the plate was blocked by adding $100 \mu \mathrm{l} 1 \% \mathrm{BSA} / \mathrm{PBS}$ to each well and was incubated for $1 \mathrm{~h}$ at $26^{\circ} \mathrm{C}$ with agitation. After a further $4 \times 3$ min with $110 \mu \mathrm{l} 0.05 \% \mathrm{PBS} /$ Tween per well, the samples, standards and blanks were added in triplicate. The samples were diluted 1:10 in 1\% BSA/ PBS and $50 \mu \mathrm{l}$ added to each sample well. Blanks were $50 \mu \mathrm{l}$ of $1 \% \mathrm{BSA} / \mathrm{PBS}$. Standards were prepared in line with the manufacturer's instructions, and $50 \mu \mathrm{l}$ was added to each well. The plate was incubated for $2 \mathrm{~h}$ at $26^{\circ} \mathrm{C}$ with agitation. After a further 4 washes, $75 \mu \mathrm{l}$ of biotinylated goat anti-human VEGF detection antibody (diluted 1:60 in $1 \% \mathrm{BSA} / \mathrm{PBS}$ ) was added to each well, and the plate then incubated for $2 \mathrm{~h}$ at $26^{\circ} \mathrm{C}$ plus agitation. After a further 4 washes, $75 \mu$ of streptavidin HRP diluted 1:40 in PBS/0.05\% Tween was added to each well and the plate incubated for $20 \mathrm{~min}$ in the dark at room temperature. After a final 4 washes, $50 \mu \mathrm{l}$ of the substrate was added to each well, and $25 \mu \mathrm{l}$ of STOP solution was added after $20 \mathrm{~min}$. Absorbance was read at $450 \mathrm{~nm}$. The intraclass correlation coefficient for this assay was 0.89 , indicating excellent consistency.

\section{Myelin-associated glycoprotein ELISA}

MAG was measured by indirect ELISA which was developed in-house [26, 27]. Autoclaved PBS was used throughout this assay. Samples were diluted 1:10 in autoclaved PBS and loaded in duplicate onto a 96-well Nunc MaxiSorp ELISA plate. Blanks consisted of $100 \mu \mathrm{l}$ of PBS and standards (Abcam ab89780) ranged from 547.6 to $8.56 \mathrm{ng} / \mathrm{ml}$. The plate was incubated for $2 \mathrm{~h}$ at $26^{\circ} \mathrm{C}$ with agitation. After 5 washes in PBS/0.05\% Tween, the plate was blocked by adding $300 \mu \mathrm{l}$ of $1 \%$ BSA/PBS per well and incubated for $1 \mathrm{~h}$ at $26^{\circ} \mathrm{C}$ with agitation. After a further 5 washes, $100 \mu \mathrm{l}$ of mouse monoclonal anti-MAG antibody (Abcam ab89780) diluted 1:1000 in PBS was added to each well. The plate was incubated for $2 \mathrm{~h}$ at $26^{\circ} \mathrm{C}$ with agitation. After a further 5 washes, $100 \mu \mathrm{l}$ of biotinylated anti-mouse antibody (Vector, diluted 1:4000 in PBS) was added to each well, and the plate incubated for $20 \mathrm{~min}$ at $26^{\circ} \mathrm{C}$ with agitation. After a further 5 washes, $100 \mu \mathrm{l}$ of streptavidin-HRP diluted 1:500 in PBS/0.01\% Tween was added to each well and the plate incubated for $20 \mathrm{~min}$ at $26^{\circ} \mathrm{C}$ with agitation. After a final 5 washes, $100 \mu$ lof the substrate was added to each well and $50 \mu \mathrm{l}$ of STOP solution added after $10 \mathrm{~min}$. Absorbance was read at $450 \mathrm{~nm}$. The intraclass correlation coefficient for this assay was 0.60 , indicating good consistency. All samples were assayed in duplicate on each plate and on two different plates.

\section{PLP ELISA}

PLP was assayed using a commercial sandwich ELISA kit (Cloud-Clone Corporation), as per the manufacturer's instructions. Samples were diluted 1:10 for this assay. Three samples were carried over on each plate to check that the results were consistent.

\section{von Willebrand factor (vWF) dot blot}

Samples were initially centrifuged again for $20 \mathrm{~min}$ at 15 , $000 \mathrm{rpm}$ to remove any particulate matter then diluted 1:400 in TBS. The standard was 7 serial dilutions of a reference homogenate, starting with a dilution of 1:100 in TBS. Prior to assembling the dot blot manifold, the membrane was soaked in TBS for at least $10 \mathrm{~min}$. One hundred microlitres of each sample was loaded onto the membrane after it had been placed in the dot blot vacuum manifold and was incubated for $75 \mathrm{~min}$. The manifold was then disassembled and the membrane washed for $3 \times 10 \mathrm{~min}$ in TTBS prior to blocking in $5 \%$ milk/ TBS for $1 \mathrm{~h}$ at room temperature with agitation. After a further $3 \times 10$-min washes in TTBS, the membrane was incubated overnight at $4{ }^{\circ} \mathrm{C}$ with agitation, in rabbit polyclonal anti-vWF antibody (Dako A0082) diluted 1:3000 in $5 \% \mathrm{milk} / \mathrm{TTBS}$. Following $3 \times 30$-min washes, the membrane was incubated in HRP conjugated goat antirabbit antibody (Vector) diluted 1:5000 in 5\% milk/TTBS for $1 \mathrm{~h}$ at room temperature with agitation. After a further $3 \times 30$-min washes, $6 \mathrm{ml}$ of the substrate was added to each membrane, and after $4 \mathrm{~min}$, it was imaged in a BioRad imager (chemiluminescence protocol). All samples were assayed in duplicate on each membrane and on two different membranes. The intraclass correlation coefficient for this assay was 0.69 , indicating good consistency.

\section{Alpha-synuclein ELISA}

Alpha-synuclein was measured in soluble and insoluble extracts by ELISA developed in-house, as described previously, adapted for use in a 384-well Nunc MaxiSorp plate $[34,35]$. The mouse monoclonal capture antibody (BD Biosciences) was diluted 1:1000 in PBS and $75 \mu \mathrm{l}$ added to each well and left overnight at room temperature. After 5 washes in $\mathrm{PBS} / 0.05 \%$ Tween, the plate was blocked by adding $100 \mu \mathrm{l}$ of $1 \%$ BSA/PBS to each well and incubating the plate at room temperature for $70 \mathrm{~min}$ with agitation. After a further 5 washes, the samples, 7 serial twofold dilutions of recombinant protein standard ( $\mathrm{R}$ peptide S-100-1) and blanks were loaded, $50 \mu \mathrm{l}$ per well in duplicate. The concentration of the standards ranged from 62.5 to $0.98 \mathrm{ng} / \mathrm{ml}$. The samples were diluted 1:400 in PBS, and the blanks consisted of $50 \mu \mathrm{l} \mathrm{PBS}$. The plate was incubated at room temperature for $90 \mathrm{~min}$ plus agitation. After a further 5 washes, $70 \mu \mathrm{l}$ of biotinylated polyclonal antibody (R\&D systems BAF1338), diluted 1:600 in 1\% BSA/PBS, was added to each well and the plate incubated for $90 \mathrm{~min}$ at room temperature with agitation. After a further 5 washes, $75 \mu \mathrm{l}$ of streptavidin-HRP diluted 1:200 in PBS/ 
$0.05 \%$ Tween was added to each well and the plate incubated for $20 \mathrm{~min}$ in the dark at room temperature with agitation. After a final 5 washes, $50 \mu \mathrm{l}$ of the substrate was added to each well, and $25 \mu \mathrm{l}$ of STOP solution was added after $20 \mathrm{~min}$. Absorbance was read at $450 \mathrm{~nm}$.

\section{Measurement of ChAT, AChE and BChE}

ChAT activity was assayed using an assay designed by Dr. Darreh-Shori's group at the Karolinska Institutet, as previously described in detail [36]. The assay was performed on 384-well plates. The wells were coated overnight at $4{ }^{\circ} \mathrm{C}$ with $100 \mu \mathrm{l}$ of monoclonal anti-ChAT (R\&D systems MAB3447) diluted 1:250 in $1 \times$ coating buffer per well except for wells which would later be used for the choline standards. After 5 washes with TBS, the samples (both native and denatured), standards and blanks were loaded. Samples were denatured by incubation at $99^{\circ} \mathrm{C}$ for $3 \times 8 \mathrm{~min} 30 \mathrm{~s}$ in a PCR machine. Ten microlitres of each sample was loaded in triplicate. Blanks consisted of dilution buffer alone. The reference standard for ChAT concentration was a pooled brain homogenate which had been prepared with $10 \times$ vol of each buffer. There were $7 \times 2$-fold dilutions of the pooled homogenate, starting with a dilution of 1:2. The choline standards for ChAT activity consisted of $8 \times 2$ fold dilutions of choline, with choline standard $\mathrm{C} 1=$ $50 \mu \mathrm{M}$. Fifty microlitres of each choline standard was loaded in triplicate. Forty microlitres of cocktail A was added to each sample/pooled homogenate/blank well. cocktail A was prepared as $4 \times$ of final concentrations and contained $10 \mu \mathrm{M}$ choline chloride, $50 \mu \mathrm{M}$ acetylCoA, $7 \mathrm{mM}$ acetyl phosphate and $1 \mathrm{unit} / \mathrm{ml}$ phosphoacetyltransferase (to continuously regenerate acetyl-CoA from -CoA generated by ChAT) in TBS buffer.

The plate was then incubated for $1 \mathrm{~h}$ at $38.5^{\circ} \mathrm{C}$ with gentle agitation. After this, $25 \mu \mathrm{l}$ of cocktail B was added to each well including those containing the choline standards, and the plate was immediately read at $500 \mathrm{~nm}$, at $1 \mathrm{~min}$ interval for $1 \mathrm{~h}$, using the kinetic mode of a Tecan M1000 spectrophotometer. The cocktail B contained 2.1 $\mathrm{mM}$ phenol, $1 \mathrm{mM}$ 4-aminoantipyrine, 0.31 units $/ \mathrm{ml}$ choline oxidase and $1 / 15,000$ streptavidin HRP in 10 mM PBS, pH 7.6.

The plate was then sealed and left overnight at $4{ }^{\circ} \mathrm{C}$. The next day, the plate was read again at $500 \mathrm{~nm}$ prior to $3 \times 5$-min washes in TBS/ $0.05 \%$ Tween. One hundred microlitres of TBS/0.05\% Tween/5\% BSA/0.1\% sodium azide was loaded into each well, and the plate was incubated for $30 \mathrm{~min}$ at $38{ }^{\circ} \mathrm{C}$ with gentle agitation. After a further 3 washes, $100 \mu \mathrm{l}$ of polyclonal anti-ChAT antibody (Abnova PAB14536) diluted 1:3500 in TBS/0.05\% Tween $/ 1 \%$ BSA $/ 0.01 \%$ sodium azide was loaded per well, and the plate was incubated for $1 \mathrm{~h}$ at $38^{\circ} \mathrm{C}$ with gentle agitation. After a further 3 washes, $75 \mu \mathrm{l}$ of polyclonal swine anti-rabbit AP diluted 1:1750 in TBS/0.05\% Tween $/ 1 \%$ BSA $/ 0.01 \%$ sodium azide was loaded per well, and the plate incubated for $30 \mathrm{~min}$ at $38^{\circ} \mathrm{C}$ with agitation. After a further 4 washes in TBS/0.05\% Tween and one wash in diethanolamine buffer $(0.022 \%$ DEA, $50 \mathrm{mM}$ $\mathrm{MgCl}_{2}, \mathrm{pH}$ 9.8), $75 \mu \mathrm{l}$ of AP substrate (para-nitrophenol, $1 \mathrm{mg} / \mathrm{ml}$ ) was loaded into each well, and the plate was read at $405 \mathrm{~nm}$, with a reference absorbance of $650 \mathrm{~nm}$. The absorbance was read immediately, at $1 \mathrm{~h}, 2 \mathrm{~h}$ and the next morning.

AChE and BChE assays were performed using a modified version of Ellman's colorimetric assay adapted to a high-throughput assay as described previously [37, 38]. Briefly, 384-well Nunc MaxiSorp plates (Merck) were coated $\mathrm{O} / \mathrm{N}$ at $4{ }^{\circ} \mathrm{C}$ with $75 \mu$ l of $1: 1000 \mathrm{HR} 2$ (anti-AChE monoclonal antibody; Thermo Fisher) and 1:2000 diluted 3E8 Ab17246 in carbonate buffer $\mathrm{pH}$ 9.5, (anti-BChE monoclonal antibody; Abcam) for AChE and $\mathrm{BChE}$ assays, respectively. The next day, the plates were emptied and washed three times with TBS (50 $\mathrm{mM}$ Tris-Cl, pH 7.5 and $150 \mathrm{mM} \mathrm{NaCl}$ ) buffer followed by blocking with carbonate buffer $\mathrm{pH}$ 9.5, containing $5 \%$ BSA for $1 \mathrm{~h}$ at room temperature (RT). Afterwards, the plates were washed three times with TBS buffer containing $0.05 \%$ Tween-20 (TBS-T) and $25 \mu \mathrm{l}$ of standards, and samples from ventral BA18 and the left occipital lobe BA19 were added in triplicate to the assigned wells. For standards, the human recombinantAChE (S1-S8 with 2 times serial dilution starting from $200 \mathrm{ng} / \mathrm{ml}$; Sigma-Aldrich, C1682) and human-BChE (S1-S8 with 2 times serial dilution starting from 34.3 ng/ml; Sigma-Aldrich, C9971) were used. Next, $50 \mu \mathrm{l}$ of master mix prepared in $\mathrm{Na} / \mathrm{K}$ phosphate buffer, containing final concentrations of $0.5 \mathrm{mM}$ acetylthiocholine iodide (ATC) or $5 \mathrm{mM}$ butyrylthiocholine iodide (BTC), $0.4 \mathrm{mM}$ 5,5'-dithiobis (2-nitrobenzoic acid) (DTNB) and $0.1 \mathrm{mM}$ ethopropazine (BChE inhibitor) or $1 \mu \mathrm{M}$ BW284c51 (AChE inhibitor; Sigma-Aldrich, A9013), were added to the $\mathrm{AChE}$ and $\mathrm{BChE}$ assay plate wells. The plates were read at $412 \mathrm{~nm}$ for $30 \mathrm{~min}$ with 2-min interval cycle using a microplate spectrophotometer reader (Infinite M1000, Tecan) to measure $\mathrm{AChE}$ and $\mathrm{BChE}$ activity $(\triangle \mathrm{OD} / \mathrm{min})$.

For AChE and BChE protein concentration estimation, an ELISA-like functional assay was used. Briefly, the plates were sealed following activity measurement and incubated for $2-3 \mathrm{~h}$ at RT. After incubation, the plates were washed two times with TBS-T buffer and read again at $412 \mathrm{~nm}$ for $60 \mathrm{~min}$ with 5-min interval cycle after adding master mix containing final concentrations of $0.5 \mathrm{mM}$ ATC or $5 \mathrm{mM}$ BTC and $0.4 \mathrm{mM}$ DTNB. The protein levels of $\mathrm{AChE}$ and $\mathrm{BChE}$ in the samples were then determined from the linear part of the standard curves as described before [39]. 


\section{Formalin-fixed tissue preparation}

The right cerebral hemisphere of each brain had been fixed for 3-4 weeks in formalin prior to being dissected into blocks and embedded in wax. The paraffin sections of the occipital cortex containing both BA18 and BA19 were cut at $7 \mu \mathrm{M}$ thickness. Immunolabelling for alphasynuclein was performed in an automated immunostainer. The mouse monoclonal anti $\alpha$-synuclein antibody (Vector VP-A106) was diluted 1:800 and applied for $1 \mathrm{~h}$ prior to DAB development of the slides.

The field fraction immunopositive for each antigen was assessed by examining up to 15 random fields of BA18 and BA19 under a $\times 20$ objective. The software package Image-Pro Plus (Media Cybernetics, MD, USA) was used to select the fields at random in the pre-defined area and for image capture. For a small number of slides, the area of BA18/19 included in the section was too small to accommodate 15 non-overlapping fields, but at least 10 were captured in all cases.

\section{Statistical analysis}

All ELISAs were adjusted for total protein content. This was done using the following formula:

$$
\text { Adjusted result }=\frac{\text { sample target protein concentration }}{\text { sample total protein concentration }}
$$

All data were analysed using parametric statistical tests such as ANOVA wherever possible. If a variable was not normally distributed and it was not possible to achieve a normal distribution by transformation, non-parametric tests were used such as the Kruskal-Wallis test. The primary outcome measure was whether the MAG:PLP1 ratio varied between the groups. For field fraction analysis, each field on each slide was given equal weighting, and mean values were compared by ANOVA, with age, gender and post-mortem interval as covariates. For a priori analyses, any demographic variable which varied between groups (e.g. age, post-mortem interval) was included as a covariate. Where Dunn's test was used, Bonferroni correction was applied. A threshold $p$ value of 0.05 was used throughout.

We estimated, using the information from a previous study [18], that we would have $89 \%$ power to detect a between-group difference in the MAG:PLP1 ratio of 0.07 .

\section{Results}

Tissue was obtained from a total of 97 individuals for both BA18 (visual processing area 2) and BA19 (visual processing area $\mathrm{V} 3$ ): 23 with $\mathrm{AD}$ and a history of visual hallucinations, 19 individuals who had Alzheimer's disease who had not suffered from visual hallucination, 19 individuals who had dementia with Lewy bodies (either with or without visual hallucinations) and 36 controls. The groups were matched for age, gender and post-mortem interval, although the $\mathrm{AD}+$ visual hallucinations group was marginally younger than the other groups $(p=0.065)$. As would be expected, the AD groups had a higher Braak stage than the other groups, and there was a between-group difference in cerebral amyloid angiopathy score, with both AD groups scoring higher [30]. Although the initial ANOVA was suggestive of a difference between the groups in disease duration, there was little evidence of a difference in the subsequent regression.

As shown in Additional file 1: Table S2, the clinical diagnosis during life frequently differed from the neuropathological diagnosis. This was more likely for the $\mathrm{AD}$ with visual hallucinations and dementia with Lewy body groups. The rate of change of diagnosis was similar to other post-mortem series $[40,41]$.

Because of the marginal difference in age between the groups, parametric analyses were carried out both with and without age as a covariate to exclude the confounding effect of a difference in age as the explanation for any between-group differences observed.

As can be seen in Table 2 and Fig. 3, there was no strong evidence of a between-group difference in VEGF, MAG, PLP1 or vWF. There was no evidence of a between-group difference in MAG:PLP1 in BA19, but unexpectedly, MAG:PLP1 seemed to be increased in all three dementia groups in BA18. There was only statistical evidence of a between-group difference between the two AD groups $(p=0.029)$. As expected from previous studies, MAG:PLP1 correlated negatively with VEGF (see Additional file 1: Figure S1) [18].

There was no evidence of a between-group difference in ChAT activity (Table 3, Additional file 1: Figure S3). AChE activity was reduced in all three dementia groups in both BA18 and BA19, as shown in Fig. 4. AChE concentration was unchanged in BA18 but was decreased in the $\mathrm{AD}$ with visual hallucinations and DLB groups in BA19. There was no evidence of a between-group difference in either BChE activity or concentration (see Additional file 1: Figure S4). ChAT activity, AChE and BChE were relatively stable with disease duration (Additional file 1: Figure S6). There was no evidence of a change in the ratio of cholinergic breakdown to production enzymes (known as the cholinergic index), as shown in Additional file 1: Figure S5.

Removing controls with a history of mental health problems, stroke or TIAs reduced the number of controls to 16. The findings in relation to $\mathrm{AChE}, \mathrm{BChE}$ and ChAT were unchanged when these controls were excluded. The evidence for a between-group difference in MAG to PLP ratio in BA18 in the opposite direction to that predicted weakened considerably, but this did not affect our overall conclusion that there was no strong 


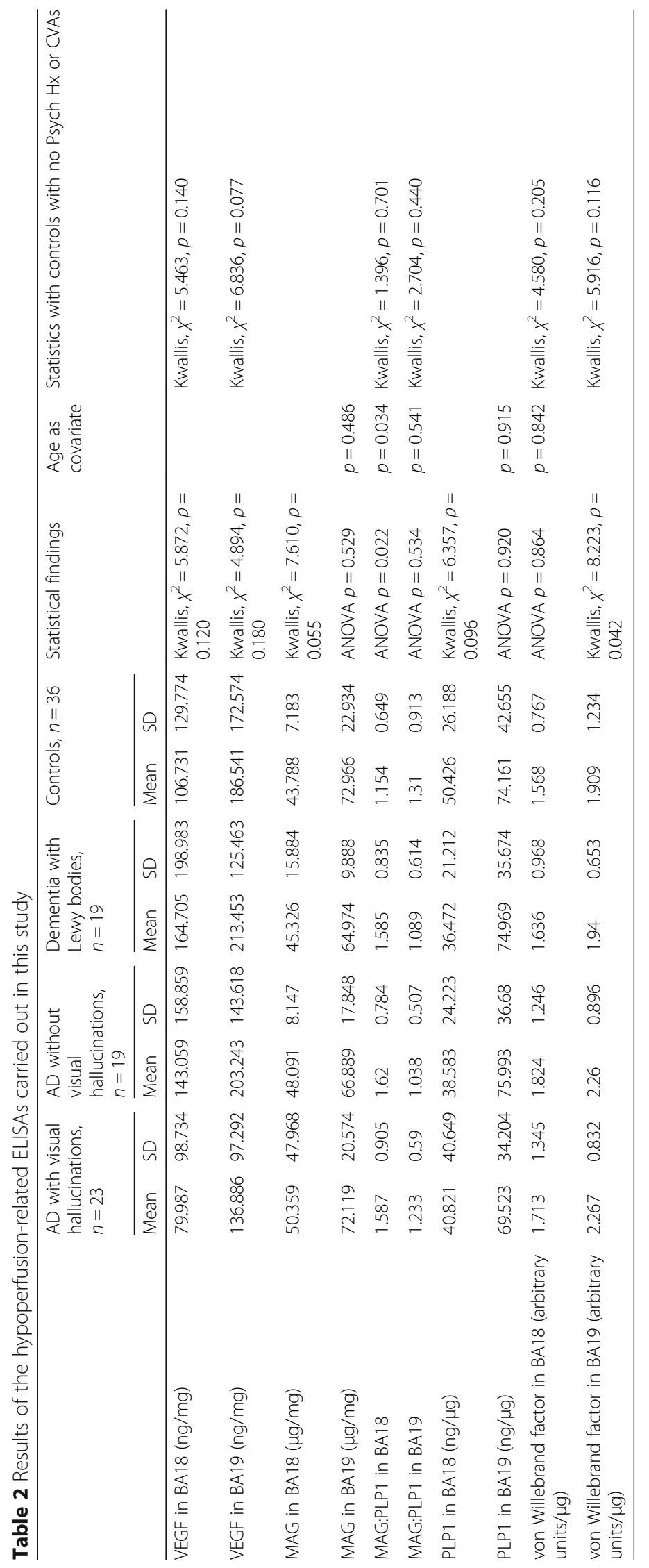


A

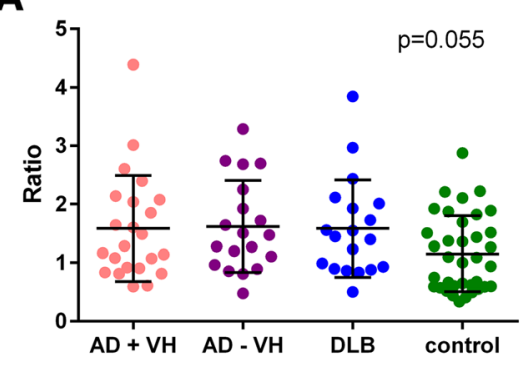

C

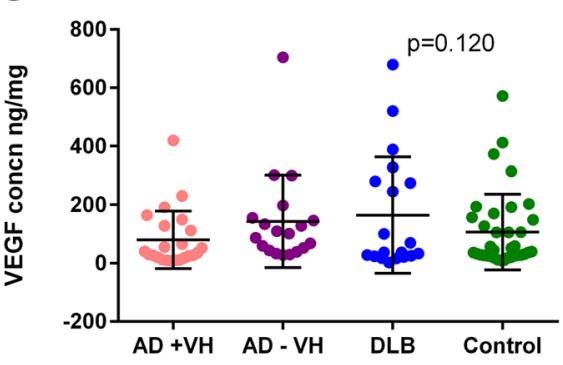

E

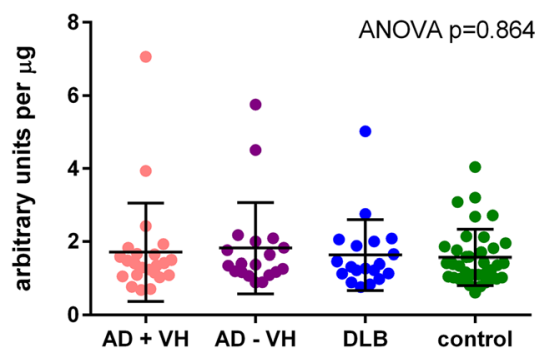

B

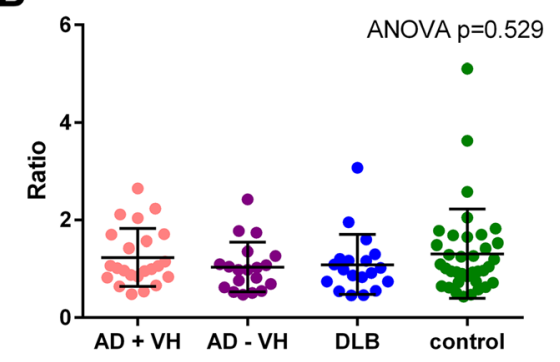

D

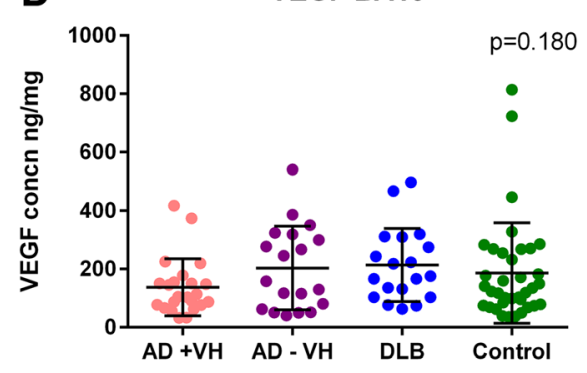

$\mathbf{F}$

VWF BA19

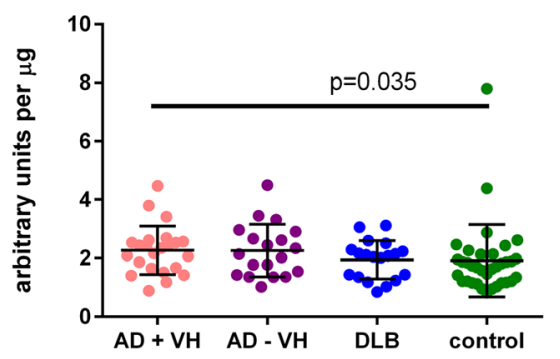

Fig. $\mathbf{3}$ There was no between-group difference in MAG:PLP1 in BA19 (b), but all three dementia groups seemed to have increased MAG:PLP1 in BA18 (a). There was no convincing between-group difference in VEGF in either BA 18 (c) or BA19 (d) or in vWF in BA18 (e). There was some evidence that VWF was increased in the AD + VH group in BA19 (f)

evidence of hypoperfusion in the occipital lobes of those with AD and visual hallucinations.

Field fraction analysis yielded no evidence of a betweengroup difference in immunolabelled $\alpha$-synuclein, but most of the values were very small (see Fig. 5 and Additional file 1: Table S4). Measurement of soluble and insoluble fractions by ELISA showed that insoluble $\alpha$-synuclein was increased in the DLB group in BA18 and 19 compared to both AD groups, as would be expected. In both brain areas, although the initial ANOVA was suggestive of a between-group difference in soluble $\alpha$-synuclein, this was not shown in the subsequent regression.

\section{Discussion}

In this relatively large post-mortem study of $\mathrm{AD}$ and DLB, we did not find any strong evidence of occipital hypoperfusion or $\alpha$-synuclein accumulation in the tissue from AD patients with visual hallucinations. There was evidence of derangement of the cholinergic equilibrium in AD and DLB: a reduction in acetylcholinesterase activity most marked in AD with visual hallucinations, but no change in the ChAT activity.

It is well known that cholinergic innervation is lost in $\mathrm{AD}$ [42], although the occipital lobe seems to be relatively spared compared to the other brain regions [43]. It was originally thought that this loss of cholinergic neurons occurred earlier in AD than in DLB, but more recent work suggests the converse [44]. The temporal cortex may be affected earlier than the other brain areas in AD. Tiraboschi et al. [44] found cholinergic loss to be greatest in the superior temporal cortex in mild AD, less in the inferior parietal and the medial frontal cortex not to be affected until moderate-severe stages of the disease. Cholinergic innervation to the occipital lobe from the nucleus basalis of Meynert was shown to be disrupted in Parkinson's disease, with increasing 

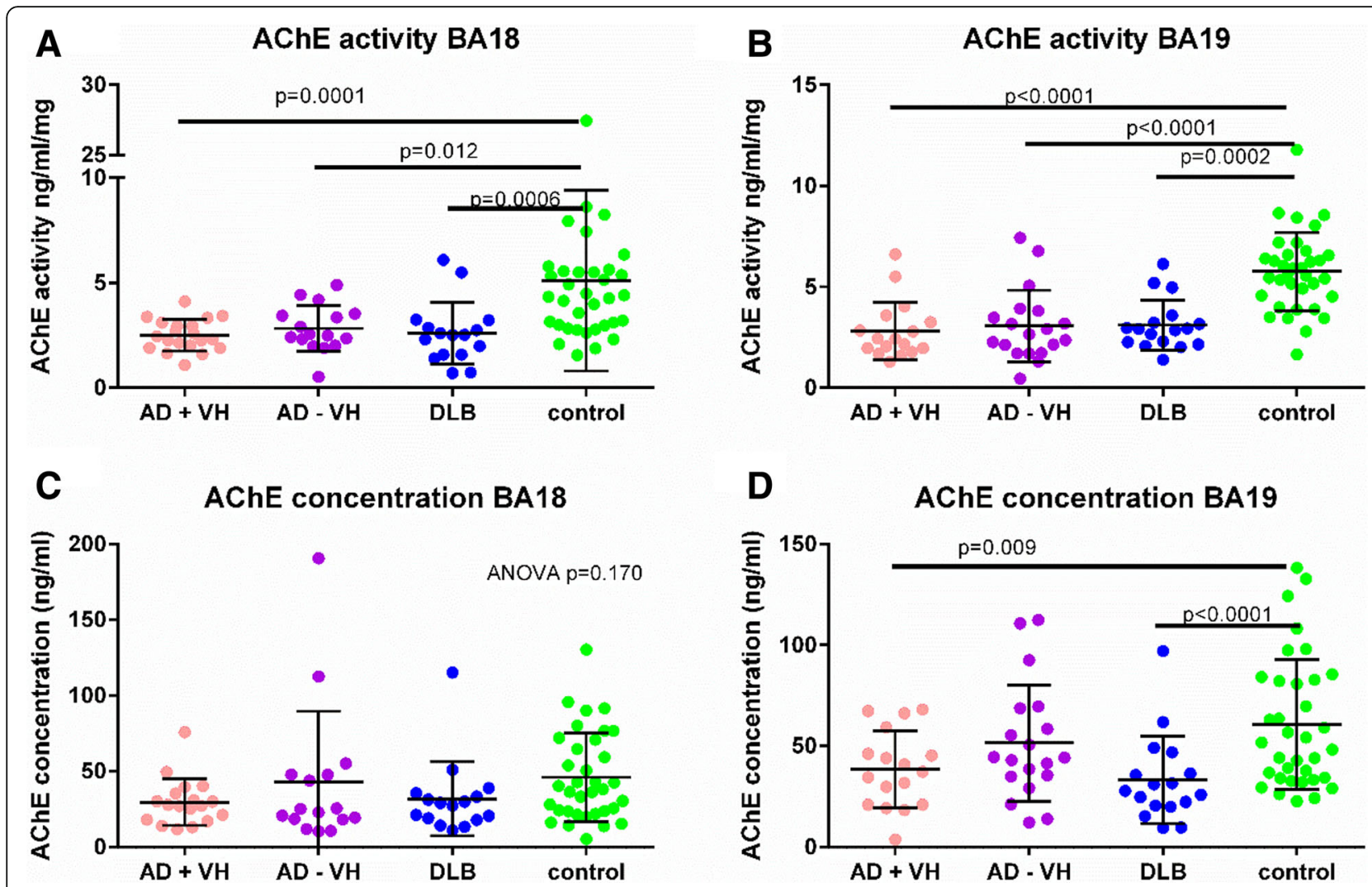

Fig. 4 Acetylcholine breakdown enzymes. AChE activity was reduced in all three dementia groups in BA18 (a) and BA19 (b). AChE concentration was decreased in the AD with VH and DLB groups in BA19 (d) but was unaltered in BA18 (c). VH, visual hallucinations

cholinergic neuronal loss with the progression of the disease [45].

Several studies have shown that cholinergic innervation of neurons in the occipital cortex influences visual attention and responses [46-48], and it is not surprising therefore that deficient cholinergic input might influence visual processing. The cholinergic activity also has the potential to influence visual processing indirectly, through its actions on the vasculature. Work in mice has demonstrated that donepezil can promote angiogenesis (by increasing HIF-1 alpha and VEGF) [21]. A study in human endothelial cells had similar findings, but only when ACh acted via muscarinic and not nicotinic receptors [49]. It is also known that cholinergic stimulation causes vasodilatation, although in some situations $\mathrm{ACh}$ is involved in vasoconstriction $[22,50,51]$. It is therefore possible, but not yet proven, that cholinergic denervation may reduce perfusion of the affected brain areas [52, 53].

Visual hallucinations have also been shown to occur earlier in DLB than in AD [54]. Visual hallucinations are rare in $\mathrm{MCI}$ but become more common in all-cause early dementia [55]. One large study based in a specialist early $\mathrm{AD}$ clinic found very low rates of $\mathrm{VH}$, and the authors commented that $\mathrm{VH}$ seemed to be more prevalent in the later stages of the illness [56], perhaps reflecting cholinergic denervation in areas of the cortex affected later on than the temporal lobe. EEG slowing in $\mathrm{AD}$ and visual hallucinations was interpreted as a potential neurophysiological indicator of cholinergic deficiency [57].

Our finding of no between-group difference in ChAT activity is in contrast to the findings of another group, in a smaller study which studied BA18/19 as a single sample. They found ChAT activity to be reduced in BA17 and BA18/19 in both DLB and AD, but with a larger reduction in DLB [17]. Our current study had similar Braak stages and longer disease duration than the previous study, so these factors cannot explain the different results. Our study used a different method for measuring ChAT activity and was also larger (particularly the control group), which may account for the discrepant findings. One explanation for the lack of difference in ChAT activity is that astrocytes are able to express ChAT on demand and this may mask a reduction in neuronal ChAT that might be caused by cholinergic neurodegeneration [36].

Although AChE hydrolyses acetylcholine more quickly than BChE, AChE is inhibited at higher concentrations of ACh. BChE is not and works more efficiently at higher concentrations. Both enzymes need to be 

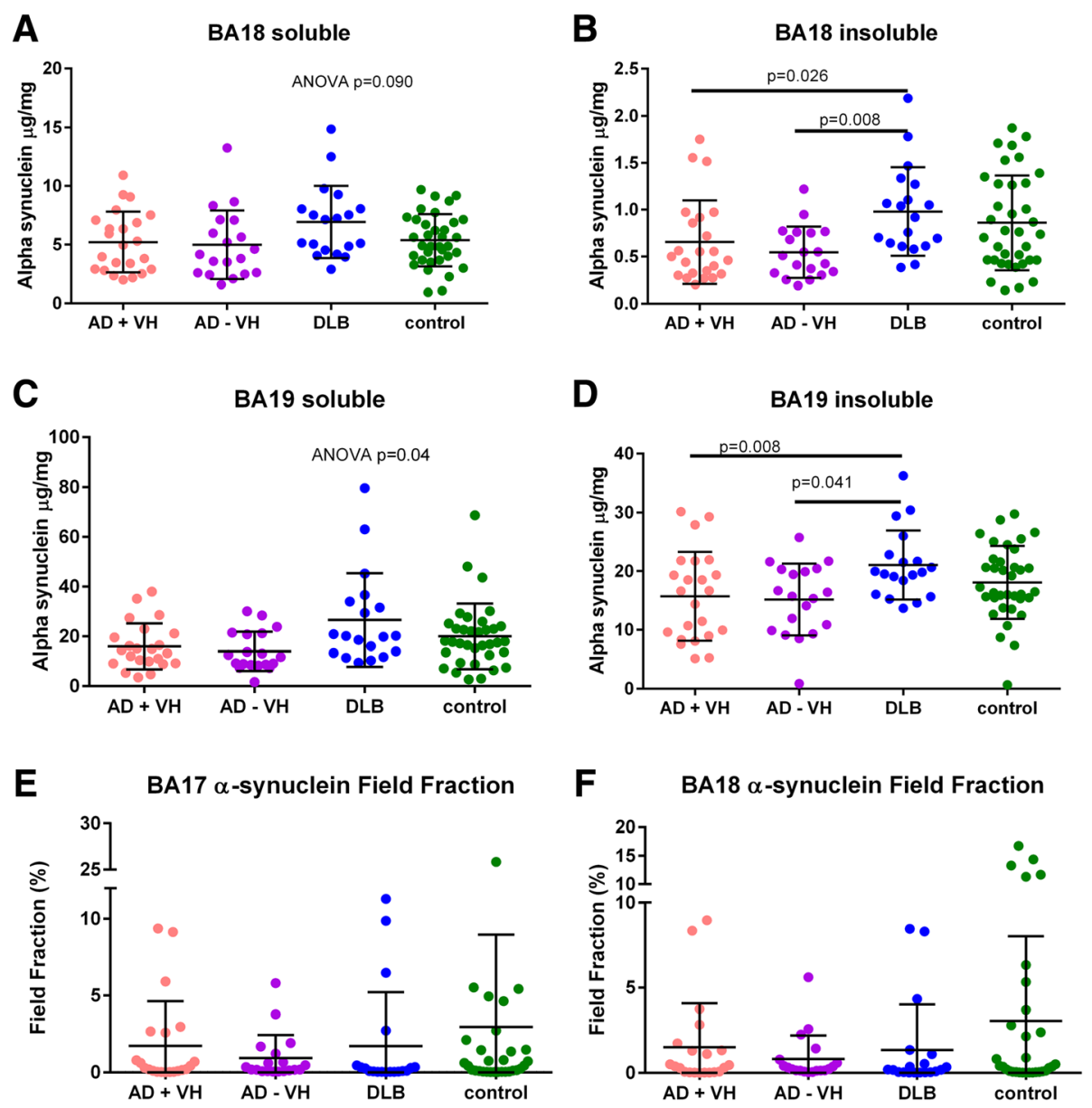

Fig. 5 a-f Results of a-synuclein ELISAs and field fraction analysis. There was no strong evidence of a between-group difference in soluble asynuclein. There was increased insoluble a-synuclein in the DLB group compared to both AD groups, but the DLB group did not differ statistically from controls. VH, visual hallucinations

measured to assess the changes in cholinergic function [58]. As there was no between-group difference in BChE, our results suggest that any differences in the cholinergic activity are occurring at lower concentrations of the neurotransmitter. Many of the patients would have taken AChE inhibitors, but it would be expected that such inhibition would, if anything, lead to an increase in AChE rather than a decrease [59]. In support of our results, $\mathrm{AChE}$ activity was found to be reduced by $27 \%$ in a small PET study of patients with DLB and Parkinson's disease dementia, especially in the medial occipital cortex [60].

A previous study by our group found evidence of chronically reduced oxygenation of primary visual cortex in DLB and evidence that this was due to reduced microvessel density rather than vasoconstriction [18]. This is important as cholinergic innervation of the blood vessels is thought to play a role in regulating cerebral blood flow by causing vasodilatation [22]. In rats, cholinergic projections from the basal forebrain have been shown to release ACh and cause vasodilation when activated [61]. As in our previous study on BA17 (primary visual cortex), MAG was slightly reduced in BA18 and BA19 in the DLB group compared to controls, although the statistical evidence for this was very weak. The MAG:PLP1 ratio was not measured in our previous study. In the present study, VEGF was raised in the DLB group, whereas it was decreased in our previous study. The differences may relate to the differences between the specific areas of the visual cortex that were assessed, but it is also noteworthy that the present study was considerably larger, the DLB and control groups both being doubled in size.

We found no between-group difference in the (very low) $\alpha$-synuclein field fraction in the occipital cortex but evidence of increased insoluble $\alpha$-synuclein in the DLB group in both BA18 and BA19. This is entirely in keeping with work by Khundakar et al. and our own group $[18,62]$. Khundakar et al. also did not demonstrate any 


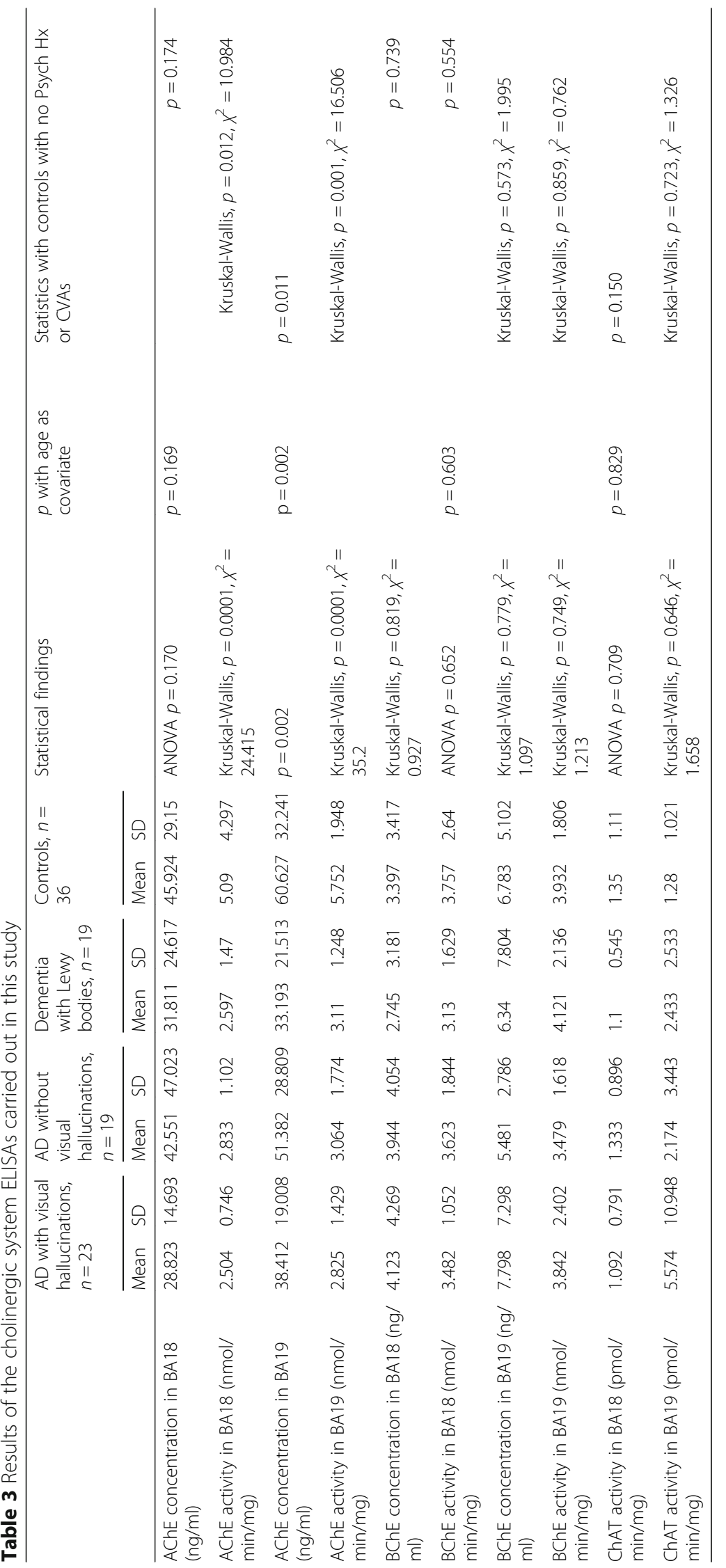


difference between DLB, AD and controls in capillary density in the visual cortex.

Strengths of our present study are the relatively large number of individuals with AD and DLB as well as the size of the control cohort. The assays yielded consistent data, giving us confidence in our results. The main weakness of this study is our reliance on the retrospective collection of data on the presence or absence of visual hallucinations. We measured indirect markers of chronic hypoperfusion, but our previous studies have shown these measures to be reliable markers of hypoperfusion in several diseases and under a wide range of post-mortem conditions. The study was limited to selected visual processing areas in the ventral occipital cortex. Future studies should assess other visual processing areas, including V4-V6. Other brain areas that have been associated with visual hallucinations, including the superior colliculus and the cuneus, should also be considered $[63,64]$.

\section{Conclusion}

In conclusion, this relatively large post-mortem brain tissue study did not show evidence of more severe $\alpha$-synuclein pathology or chronic hypoperfusion in the ventral visual processing areas $\mathrm{V} 2$ and $\mathrm{V} 3$ in $\mathrm{AD}$ with visual hallucinations, compared to $\mathrm{AD}$ without visual hallucinations or controls. There was also no difference in the ChAT activity. However, AChE activity was reduced in DLB and AD and particularly so in AD with visual hallucinations.

\section{Additional file}

Additional file 1: Figure S1. As can be seen, MAG:PLP1 correlated negatively with VEGF, although the relationship was relatively weak. Figure S2. ChAT concentration. There was no between-group difference in ChAT concentration in either BA18 (A) or BA19 (B). VH = visual hallucinations. Figure S3. ChAT activity. There was no significant between-group difference in ChAT activity in either brain area. Figure S4. Neither BChE activity nor concentration differed between the groups in either brain area. There was little relationship between either AChE or $\mathrm{BChE}$ activity and protein concentration, suggesting that some of the enzyme present was inactive. Figure S5. Examining the relationship between ChAT activity and the activity of cholinergic breakdown enzymes. The cholinergic index in A and B was calculated as ChAT activity/AChE activity + BChE activity. In $C$ and $D$, the ration of ChAT activity to AChE activity alone is shown. Figure S6. Cholinergic markers and disease duration. ChAT activity (A and B), AChE activity (C and D) and BChE activity ( $E$ and $F$ ) activity did not change significantly with disease duration. Table S1. a-Synuclein results. Table S2. Comparison between diagnosis in life and the pathological diagnosis made postmortem. The most common diagnosis listed in the other dementia column was unspecified "dementia" or "senile dementia". Table S3. Further details on medical history for the

individuals whose donated tissue was used in this study. The "other neurological diagnoses" included epilepsy late on in dementia (3 people), minor head injuries, vascular Parkinsonism (1 person) and possible SLE (1 person). It was apparent that some individuals were treated with antipsychotics to control distress at the end of their lives, rather than to treat psychotic symptoms. (DOCX $772 \mathrm{~kb}$ )

\section{Abbreviations}

AChE: Acetylcholinesterase; AD: Alzheimer's disease; BA17: Brodmann area 17; BA18: Brodmann area 18; BA19: Brodmann area 19;

BChE: Butyrlcholinesterase; ChAT: Cholineacetyltransferase; DLB: Dementia with Lewy bodies; DSM-IV: Diagnostic and statistical manual of mental disorders, 4th edition; ELISA: Enzyme-linked immunosorbent assay;

MAG: Myelin-associated glycoprotein; NP-40: 4-Nonylphenyl poly (ethylene glycol); PBS: Phosphate-buffered saline; PET: Positron emission tomography; PLP: Phospholipoprotein 1; SDS: Sodium dodecyl sulphate; SPECT: Singlephoton emission computed tomography; TBS: Tris-buffered saline;

VEGF: Vascular endothelial growth factor; VH: Visual hallucinations; VWF: von Willebrand Factor

\section{Acknowledgements}

We thank Vinay Mandagere for the assistance with the sample preparation and measurement of total protein.

\section{Authors' contributions}

LS and SL had the original idea. LS performed the VEGF, MAG, PLP1, VWF and ChAT ELISAs; analysed the data; and wrote the initial draft of the paper. AK performed the AChE and BChE ELISAs. TS contributed to the design of the ChAT, AChE and BChE component of the work and supervised those assays including the data analysis. All authors contributed to the written paper and reviewed the results of the data analysis. All authors read and approved the final manuscript.

\section{Funding}

This work was funded by a pilot grant from the Mason Medical Research Foundation and by a Margaret Slack Travelling Fellowship from the Royal College of Psychiatrists. We are grateful to the South West Dementia Brain Bank for providing the tissue used in this study. The South West Dementia Brain Bank is supported by BRACE (Bristol Research into Alzheimer's and Care of the Elderly), by the Medical Research Council and by Alzheimer's Research UK and the Alzheimer's Society as part of the Brains for Dementia Research.

\section{Availability of data and materials}

Unfortunately, the fresh tissue samples used in this paper are not available. The raw data are available on request, subject to the conditions of the ethical approval.

\section{Ethics approval and consent to participate}

The study used brain tissue and clinical data obtained from the South West Dementia Brain Bank (SWDBB), University of Bristol, with local Research Ethics Committee approval (REC reference 18/SW/0029).

\section{Consent for publication}

N/A

\section{Competing interests}

The authors declare that they have no competing interests.

\section{Author details}

'Population Health Sciences, Oakfield House, University of Bristol, Clifton, Bristol BS8 2BN, UK. ${ }^{2}$ Translational Health Sciences, Level 1 Learning \& Research Building, Southmead Hospital, University of Bristol, Bristol BS10 5NB, UK. ${ }^{3}$ Division of Clinical Geriatrics, NEO Plan 7, Department of Neurobiology, Care Sciences and Society (NVS), H1, 14152 Huddinge, Sweden.

Received: 18 February 2019 Accepted: 8 July 2019

Published online: 12 September 2019

\section{References}

1. Alzheimer's Association. Alzheimer's disease facts and figures. Alzheimers Dement. 2015;11:332-84.

2. Steinberg M, Shao H, Zandi P, Lyketsos CG, Welsh-Bohmer KA, Norton MC Breitner JCS, Steffens DC, Tschanz JT, Cache County I. Point and 5-year 
period prevalence of neuropsychiatric symptoms in dementia: the Cache County Study. Int J Geriatr Psychiatry. 2008;23:170-7.

3. Maher A, Maglione M, Bagley S, et al. Efficacy and comparative effectiveness of atypical antipsychotic medications for off-label uses in adults: a systematic review and meta-analysis. JAMA. 2011;306:1359-69.

4. McKeith IG, Dickson DW, Lowe J, Emre M, O'Brien JT, Feldman H, Cummings J, Duda JE, Lippa C, Perry EK, et al. Diagnosis and management of dementia with Lewy bodies: third report of the DLB Consortium. Neurology. 2005;65:1863-72.

5. Hansen L, Salmon D, Galasko D, Masliah E, Katzman R, DeTeresa R, Thal L, Pay MM, Hofstetter R, Klauber M, et al. The Lewy body variant of Alzheimer's disease: a clinical and pathologic entity. Neurology. 1990;40:1-8.

6. Tsuang D, Larson EB, Bolen E, Thompson ML, Peskind E, Bowen J, McCormick W, Teri L, Kukull W, Vavrek D, et al. Visual hallucinations in dementia: a prospective community-based study with autopsy. Am J Geriatr Psychiatry. 2009;17:317-23.

7. Jacobson SA, Morshed T, Dugger BN, Beach TG, Hentz JG, Adler CH, Shill HA, Sabbagh MN, Belden CM, Sue LI, et al. Plaques and tangles as well as Lewy-type alpha synucleinopathy are associated with formed visual hallucinations. Parkinsonism Relat Disord. 2014;20:1009-14.

8. Tsuang D, Simpson K, Larson EB, Peskind E, Kukull W, Bowen JB, McCormick W, Teri L, Montine T, Thompson ML, Leverenz JB. Predicting Lewy body pathology in a community-based sample with clinical diagnosis of Alzheimer's disease. J Geriatr Psychiatry Neurol. 2006;19:195-201.

9. Chiu P-Y, Hsu M-H, Wang C-W, Tsai C-T, Pai M-C. Visual hallucinations in Alzheimer's disease is significantly associated with clinical diagnostic features of dementia with Lewy bodies. PLoS One. 2017;12:e0186886.

10. Chung E, Babulal GM, Monsell SE, Cairns NJ, Roe CM, Morris JC. CLinical features of Alzheimer disease with and without Lewy bodies. JAMA Neurol. 2015;72:789-96.

11. Lobotesis K, Fenwick JD, Phipps A, Ryman A, Swann A, Ballard C, McKeith IG, O'Brien JT. Occipital hypoperfusion on SPECT in dementia with Lewy bodies but not AD. Neurology. 2001:56:643-9.

12. Matsui H, Nishinaka K, Oda M, Hara N, Komatsu K, Kubori T, Udaka F. Hypoperfusion of the visual pathway in parkinsonian patients with visual hallucinations. Mov Disord. 2006;21:2140-4.

13. Ishii K, Imamura T, Sasaki M, Yamaji S, Sakamoto S, Kitagaki H, Hashimoto M, Hirono N, Shimomura T, Mori E. Regional cerebral glucose metabolism in dementia with Lewy bodies and Alzheimer's disease. Neurology. 1998;51: 125-30.

14. Firbank MJ, Lloyd J, O'Brien JT. The relationship between hallucinations and FDG-PET in dementia with Lewy bodies. Brain Imaging Behav. 2016;10:636-9.

15. Shimizu S, Kanetaka H, Hirao K, Fukasawa R, Namioka N, Hatanaka H, Hirose D, Umahara T, Sakurai H, Hanyu H. Neuroimaging for diagnosing dementia with Lewy bodies: what is the best neuroimaging technique in discriminating dementia with Lewy bodies from Alzheimer's disease? Geriatr Gerontol Int. 2017;17:819-24.

16. McKeith IG, Boeve BF, Dickson DW, Halliday G, Taylor J-P, Weintraub D, Aarsland D, Galvin J, Attems J, Ballard CG, et al. Diagnosis and management of dementia with Lewy bodies: fourth consensus report of the DLB Consortium. Neurology. 2017;89:88-100

17. Mukaetova-Ladinska EB, Andras A, Milne J, Abdel-All Z, Borr I, Jaros E, Perry $\mathrm{RH}$, Honer WG, Cleghorn A, Doherty J, et al. Synaptic proteins and choline acetyltransferase loss in visual cortex in dementia with Lewy bodies. J Neuropathol Exp Neurol. 2013;72:53-60.

18. Miners $\mathrm{S}$, Moulding $\mathrm{H}$, de Silva $\mathrm{R}$, Love $\mathrm{S}$. Reduced vascular endothelial growth factor and capillary density in the occipital cortex in dementia with Lewy bodies. Brain Pathol. 2014;24:334-43.

19. Mori E, Ikeda M, Kosaka K, Donepezil DLBSI. Donepezil for dementia with Lewy bodies: a randomized, placebo-controlled trial. Ann Neurol. 2012;72:41-52.

20. Mori T, Ikeda M, Fukuhara R, Nestor PJ, Tanabe H. Correlation of visual hallucinations with occipital rCBF changes by donepezil in DLB. Neurology. 2006:66:935-7.

21. Kakinuma Y, Furihata M, Akiyama T, Arikawa M, Handa T, Katare RG, Sato T. Donepezil, an acetylcholinesterase inhibitor against Alzheimer's dementia, promotes angiogenesis in an ischemic hindlimb model. J Mol Cell Cardiol. 2010:48:680-93.

22. Bohnen NI, Albin RL. The cholinergic system and Parkinson disease. Behav Brain Res. 2011;221:564-73.

23. Collerton D, Perry E, McKeith I. Why people see things that are not there: a novel Perception and Attention Deficit model for recurrent complex visual hallucinations. Behav Brain Sci. 2005;28:737-57.
24. Yu AJ, Dayan P. Acetylcholine in cortical inference. Neural Netw. 2002;15: 719-30.

25. Perry EK, Marshall E, Kerwin J, Smith CJ, Jabeen S, Cheng AV, Perry RH Evidence of a monoaminergic-cholinergic imbalance related to visual hallucinations in Lewy body dementia. J Neurochem. 1990;55:1454-6.

26. Barker $\mathrm{R}$, Wellington $\mathrm{D}$, Esiri MM, Love $\mathrm{S}$. Assessing white matter ischemic damage in dementia patients by measurement of myelin proteins. J Cereb Blood Flow Metab. 2013;33:1050-7.

27. Barker R, Ashby EL, Wellington D, Barrow VM, Palmer JC, Kehoe PG, Esiri MM, Love S. Pathophysiology of white matter perfusion in Alzheimer's disease and vascular dementia. Brain. 2014;137:1524-32.

28. Thomas T, Miners S, Love S. Post-mortem assessment of hypoperfusion of cerebral cortex in Alzheimer's disease and vascular dementia. Brain. 2015; 138:1059-69.

29. Reeves SJ, Clark-Papasavas C, Gould RL, Ffytche D, Howard RJ. Cognitive phenotype of psychotic symptoms in Alzheimer's disease: evidence for impaired visuoperceptual function in the misidentification subtype. Int J Geriatr Psychiatry. 2015;30:1147-55.

30. Chalmers K, Wilcock GK, Love S. APOE\&4 influences the pathological phenotype of Alzheimer's disease by favouring cerebrovascular over parenchymal accumulation of $A \beta$ protein. Neuropathol Appl Neurobiol. 2003;29:231-8.

31. APA. Diagnostic and statistical manual of mental disorders (4th ed., text rev.). 4th ed. Washington DC: American Psychological Association; 2000.

32. Montine TJ, Phelps CH, Beach TG, Bigio EH, Cairns NJ, Dickson DW, Duyckaerts C, Frosch MP, Masliah E, Mirra SS, et al. National Institute on Aging-Alzheimer's Association guidelines for the neuropathologic assessment of Alzheimer's disease: a practical approach. Acta Neuropathol. 2012;123:1-11.

33. Peng JH, McGeer PL, Kimura H, Sung SC, McGeer EG. Purification and immunochemical properties of choline acetyltransferase from human brain. Neurochem Res. 1980;5:943-62.

34. Swirski M, Miners JS, de Silva R, Lashley T, Ling H, Holton J, Revesz T, Love S. Evaluating the relationship between amyloid- $\beta$ and a-synuclein phosphorylated at Ser129 in dementia with Lewy bodies and Parkinson's disease. Alzheimers Res Ther. 2014;6:77.

35. Miners JS, Renfrew R, Swirski M, Love S. Accumulation of a-synuclein in dementia with Lewy bodies is associated with decline in the a-synucleindegrading enzymes kallikrein-6 and calpain-1. Acta Neuropathol Commun. 2014;2:164.

36. Vijayaraghavan S, Karami A, Aeinehband S, Behbahani H, Grandien A, Nilsson B, Ekdahl KN, Lindblom RPF, Piehl F, Darreh-Shori T. Regulated extracellular choline acetyltransferase activity - the plausible missing link of the distant action of acetylcholine in the cholinergic anti-inflammatory pathway. PLoS One. 2013;8:e65936.

37. Kumar A, Darreh-Shori T. DMSO: a mixed-competitive inhibitor of human acetylcholinesterase. ACS Chem Neurosci. 2017:8:2618-25.

38. Kumar R, Langstrom B, Darreh-Shori T. Novel ligands of choline acetyltransferase designed by in silico molecular docking, hologram QSAR and lead optimization. Sci Rep. 2016;6:31247.

39. Darreh-Shori T, Kadir A, Almkvist O, Grut M, Wall A, Blomquist G, Eriksson B, Langstrom B, Nordberg A. Inhibition of acetylcholinesterase in CSF versus brain assessed by 11C-PMP PET in AD patients treated with galantamine. Neurobiol Aging. 2008;29:168-84

40. Selvackadunco S, Langford K, Shah Z, Hurley S, Bodi I, King A, Aarsland D, Troakes C, Al-Sarraj S. Comparison of clinical and neuropathological diagnoses of neurodegenerative diseases in two centres from the Brains for Dementia Research (BDR) cohort. J Neural transm (Vienna). 2019;126: 327-37.

41. Beach TG, Monsell SE, Phillips LE, Kukull W. Accuracy of the clinical diagnosis of Alzheimer disease at National Institute on Aging Alzheimer Disease Centers, 2005-2010. J Neuropathol Exp Neurol. 2012;71:266-73.

42. Geula C, Mesulam MM. Cortical cholinergic fibers in aging and Alzheimer's disease: a morphometric study. Neuroscience. 1989;33:469-81.

43. Geula C, Mesulam MM. Systematic regional variations in the loss of cortical cholinergic fibers in Alzheimer's disease. Cereb Cortex. 1996;6:165-77.

44. Tiraboschi P, Hansen LA, Alford M, et al. Early and widespread cholinergic losses differentiate dementia with Lewy bodies from Alzheimer disease. Arch Gen Psychiatry. 2002;59:946-51.

45. Liu AKL, Chang RC-C, Pearce RKB, Gentleman SM. Differential subregional nucleus basalis of Meynert pathology in Lewy body disorders and 
Alzheimer's disease. In: 11th European Congress of Neuropathology. Bordeaux; 2016.

46. Bentley P, Husain M, Dolan RJ. Effects of cholinergic enhancement on visual stimulation, spatial attention, and spatial working memory. Neuron. 2004;41: 969-82. https://www.sciencedirect.com/science/article/pii/S0896627304 00145X?via\%3Dihub.

47. Ricciardi E, Handjaras G, Bernardi G, Pietrini P, Furey ML. Cholinergic enhancement reduces functional connectivity and BOLD variability in visual extrastriate cortex during selective attention. Neuropharmacology. 2013:64:305-13.

48. Bentley $P$, Vuilleumier $P$, Thiel CM, Driver J, Dolan RJ. Effects of attention and emotion on repetition priming and their modulation by cholinergic enhancement. J Neurophysiol. 2003;90:1171-81.

49. Dhein S, Wermke A, von Salisch S, Schlegel F, Stepan H, Dohmen PM, Kostelka M, Mohr F-W. Autocrine control of angiogenesis by endogenous acetylcholine in an in vitro model using human endothelial cells: evidence for an autocrine cholinergic system in endothelial cells. J Cardiovasc Pharmacol. 2015;65:508-15.

50. Scremin OU, Scremin AME, Heuser D, Hudgell R, Romero E, Imbimbo BP. Prolonged effects of cholinesterase inhibition with eptastigmine on the cerebral blood flow-metabolism ratio of normal rats. J Cereb Blood Flow Metab. 1993;13:702-11

51. Librizzi L, Folco G, de Curtis M. Nitric oxide synthase inhibitors unmask acetylcholine-mediated constriction of cerebral vessels in the in vitro isolated guinea-pig brain. Neuroscience. 2000;101:283-7.

52. Van Beek AHEA, Claassen JAHR. The cerebrovascular role of the cholinergic neural system in Alzheimer's disease. Behav Brain Res. 2011; 221:537-42.

53. Elhusseiny A, Cohen Z, Olivier A, Stanimirović DB, Hamel E. Functional acetylcholine muscarinic receptor subtypes in human brain microcirculation: identification and cellular localization. J Cereb Blood Flow Metab. 1999;19: 794-802.

54. Ferman TJ, Arvanitakis Z, Fujishiro H, Duara R, Parfitt F, Purdy M, Waters C, Barker W, Graff-Radford NR, Dickson DW. Pathology and temporal onset of visual hallucinations, misperceptions and family misidentification distinguishes dementia with Lewy bodies from Alzheimer's disease. Parkinsonism Relat Disord. 2013;19:227-31.

55. Lyketsos CG, Lopez O, Jones B, Fitzpatrick AL, Breitner J, DeKosky S. Prevalence of neuropsychiatric symptoms in dementia and mild cognitive impairment: results from the cardiovascular health study. JAMA. 2002;288: 1475-83.

56. Linszen MMJ, Lemstra AW, Dauwan M, Brouwer RM, Scheltens P, Sommer IEC. Understanding hallucinations in probable Alzheimer's disease: very low prevalence rates in a tertiary memory clinic. Alzheimers Dement. 2018;10: 358-62.

57. Dauwan M, Linszen MMJ, Lemstra AW, Scheltens P, Stam CJ, Sommer IE. EEG-based neurophysiological indicators of hallucinations in Alzheimer's disease: comparison with dementia with Lewy bodies. Neurobiol Aging. 2018;67:75-83

58. Hartmann J, Kiewert C, Duysen EG, Lockridge O, Greig NH, Klein J. Excessive hippocampal acetylcholine levels in acetylcholinesterase-deficient mice are moderated by butyrylcholinesterase activity. J Neurochem. 2007;100:1421-9.

59. Darreh-Shori T, Soininen $\mathrm{H}$. Effects of cholinesterase inhibitors on the activities and protein levels of cholinesterases in the cerebrospinal fluid of patients with Alzheimer's disease: a review of recent clinical studies. Curr Alzheimer Res. 2010;7:67-73.

60. Shimada H, Hirano S, Shinotoh H, Aotsuka A, Sato K, Tanaka N, Ota T, Asahina M, Fukushi K, Kuwabara $\mathrm{S}$, et al. Mapping of brain acetylcholinesterase alterations in Lewy body disease by PET. Neurology. 2009; $73: 273-8$

61. Sato A, Sato Y, Uchida S. Regulation of cerebral cortical blood flow by the basal forebrain cholinergic fibers and aging. Autonomic Neurosci. 2002;96:13-9.

62. Khundakar AA, Hanson PS, Erskine D, Lax NZ, Roscamp J, Karyka E, Tsefou E, Singh P, Cockell SJ, Gribben A, et al. Analysis of primary visual cortex in dementia with Lewy bodies indicates GABAergic involvement associated with recurrent complex visual hallucinations. Acta Neuropathol Commun. 2016;4:66.

63. Erskine D, Thomas AJ, Taylor J-P, Savage MA, Attems J, McKeith IG, Morris CM, Khundakar AA. Neuronal loss and A-synuclein pathology in the superior colliculus and its relationship to visual hallucinations in dementia with Lewy bodies. Am J Geriatr Psychiatry. 2017;25:595-604.
64. Blanc F, Colloby SJ, Cretin B, de Sousa PL, Demuynck C, O'Brien JT, MartinHunyadi C, McKeith I, Philippi N, Taylor J-P. Grey matter atrophy in prodromal stage of dementia with Lewy bodies and Alzheimer's disease. Alzheimers Res Ther. 2016;8:31.

\section{Publisher's Note}

Springer Nature remains neutral with regard to jurisdictional claims in published maps and institutional affiliations.
Ready to submit your research? Choose BMC and benefit from:

- fast, convenient online submission

- thorough peer review by experienced researchers in your field

- rapid publication on acceptance

- support for research data, including large and complex data types

- gold Open Access which fosters wider collaboration and increased citations

- maximum visibility for your research: over $100 \mathrm{M}$ website views per year

At $\mathrm{BMC}$, research is always in progress.

Learn more biomedcentral.com/submissions 